REVUE DE L'INSTITUT

FRANC AIS D'HISTOIRE

EN ALLEMAGNE

\section{Revue de l'IFHA}

Revue de l'Institut français d'histoire en Allemagne

$6 \mid 2014$

IFHA 6

\title{
Conférence de Stéphane Audoin-Rouzeau « Mort des jeunes, mort des étudiants en 1914-1918 »
}

Francfort-sur-le-Main, 11 septembre 2014

\section{Pierre Monnet}

\section{OpenEdition}

\section{Journals}

Édition électronique

URL : http://journals.openedition.org/ifha/8003

DOI : 10.4000/ifha.8003

ISSN : 2198-8943

Éditeur

IFRA - Institut franco-allemand (sciences historiques et sociales)

Édition imprimée

Date de publication : 31 décembre 2014

ISSN : 2190-0078

Référence électronique

Pierre Monnet, «Conférence de Stéphane Audoin-Rouzeau « Mort des jeunes, mort des étudiants en

1914-1918 » », Revue de l'IFHA [En ligne], 6 | 2014, mis en ligne le 31 décembre 2014, consulté le 03 mai 2019. URL : http://journals.openedition.org/ifha/8003 ; DOI : 10.4000/ifha.8003

Ce document a été généré automatiquement le 3 mai 2019.

(C)IFHA 


\title{
Conférence de Stéphane Audoin- Rouzeau « Mort des jeunes, mort des étudiants en 1914-1918 »
}

Francfort-sur-le-Main, 11 septembre 2014

\author{
Pierre Monnet
}

1 Dans le cadre du cycle des manifestations organisées, co-organisées ou simplement soutenues par l'IFHA avec ses partenaires culturels et scientifiques, à l'occasion du centenaire des débuts de la Première Guerre mondiale, à Francfort en 2014, s'est tenu un colloque organisé par l'Institut für Jugendbuchforschung de l'université Goethe de Francfort (voir compte rendu dans le présent numéro de notre Revue). Ce centre de recherche consacré à la littérature de jeunesse dans une approche internationale, pluridisciplinaire et comparée, a organisé du 10 au 12 septembre 2014 une rencontre internationale consacrée à «La Première Guerre mondiale. Enfance et jeunesse en guerre, littérature, cultures de la mémoire ». L'IFHA a été associé à cette manifestation et, au cœur des travaux des intervenants du colloque, a organisé la venue de Stéphane Audoin-Rouzeau, Directeur d'études à l'EHESS, spécialiste de l'histoire de la Première Guerre mondiale et président du Centre international de recherche de l'Historial de la Grande Guerre de Péronne, dans la Somme.

2 Le thème de sa conférence, consacré à la mort en masse de jeunes lycéens, étudiants, élèves des grandes écoles, en France, entre 1914-1918, et aux effets de cette véritable fauche d'une jeune génération sur les mentalités, la littérature, l'esprit intellectuel de l'après-guerre, mais aussi sur leurs familles, leurs camarades et les souvenirs qui y sont associés, s'insérait parfaitement dans la thématique générale du colloque. Le sujet était en même temps suffisamment ouvert à la comparaison, à la discussion, au questionnement entre les disciplines (histoire, anthropologie, psychologie, littérature, art...), pour qu'un large public y assiste, au-delà des seuls participants scientifiques du colloque.

C'est la raison pour laquelle l'IFHA a résolu de filmer l'ensemble de cette intervention et, avec la permission de son auteur, a pu en placer sur le net une version sous-titrée en 
allemand. On peut voir cette conférence filmée en cliquant sur le lien fourni par le site de www.ifha.fr.

\section{AUTEUR}

PIERRE MONNET

(EHESS, Paris et IFHA, Francfort-sur-le-Main) 